
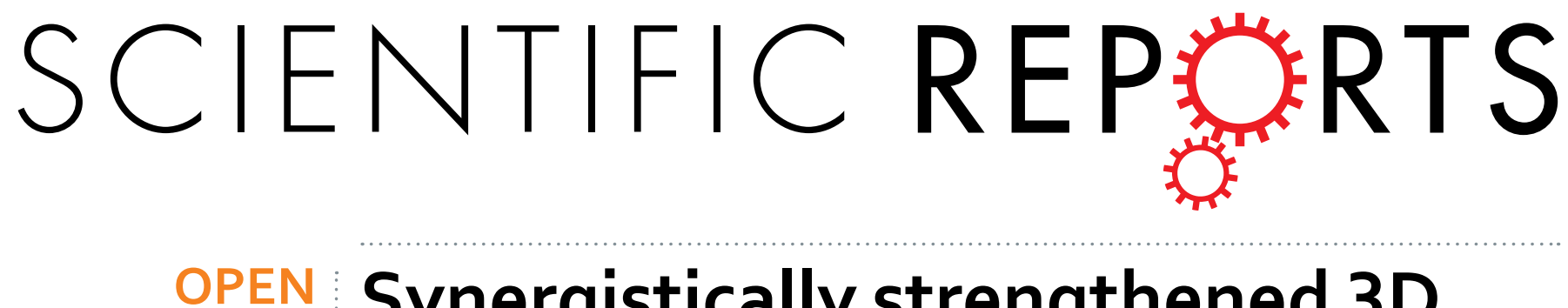

\title{
Synergistically strengthened 3D micro-scavenger cage adsorbent for selective removal of radioactive
}

Received: 16 June 2016

Accepted: 09 November 2016

Published: 05 December 2016

\section{cesium}

\author{
Sung-Chan Jang ${ }^{1,2, *}$, Sung-Min Kang ${ }^{1,3, *}$, Yuvaraj Haldorai ${ }^{4}$, Krishnan Giribabu ${ }^{1}$, \\ Go-Woon Lee ${ }^{1,5}$, Young-Chul Lee ${ }^{6}$, Moon Seop Hyun ${ }^{7}$, Young-Kyu Han ${ }^{4}$, Changhyun Roh ${ }^{2,8}$ \& \\ Yun Suk Huh ${ }^{1}$
}

A novel microporous three-dimensional pomegranate-like micro-scavenger cage (P-MSC) composite has been synthesized by immobilization of iron phyllosilicates clay onto a Prussian blue (PB)/alginate matrix and tested for the removal of radioactive cesium from aqueous solution. Experimental results show that the adsorption capacity increases with increasing the inactive cesium concentration from $1 \mathrm{ppm}$ to $30 \mathrm{ppm}$, which may be attributed to greater number of adsorption sites and further increase in the inactive cesium concentration has no effect. The P-MSC composite exhibit maximum adsorption capacity of $108.06 \mathrm{mg}$ of inactive cesium per gram of adsorbent. The adsorption isotherm is better fitted to the Freundlich model than the Langmuir model. In addition, kinetics studies show that the adsorption process is consistent with a pseudo second-order model. Furthermore, at equilibrium, the composite has an outstanding adsorption capacity of $99.24 \%$ for the radioactive cesium from aqueous solution. This may be ascribed to the fact that the AIP clay played a substantial role in protecting PB release from the $\mathrm{P}$-MSC composite by cross-linking with alginate to improve the mechanical stability. Excellent adsorption capacity, easy separation, and good selectivity make the adsorbent suitable for the removal of radioactive cesium from seawater around nuclear plants and/or after nuclear accidents.

The tsunami that followed the earthquake on March 11, 2011 at the Fukushima Daiichi nuclear plant resulted in releasing a radioactive contaminant into the seawater that contains highly radioactive cesium, which is currently present in a wide area of eastern Japan after the tsunami caused a power outage, a subsequent loss of control, and a cooling system failure ${ }^{1,2}$. Soon after the nuclear accident, Japan's Ministry of the Environment reported readings of radioactive cesium seawater as high as 45.5 million $\mathrm{Bq} / \mathrm{m}^{3}$. The radioactive cesium radionuclide, which has a half-life of 30 years, is hazardous as it exerts toxic effects via emission of beta-particles and strong gamma rays. If humans are exposed to radioactive cesium, it is rapidly distributed throughout all muscle tissue, and severe arrhythmia, heart failure, or sudden death can result from the accumulation of radioactive cesium in cardiac muscle $^{3,4}$. Several researchers have suggested using physical adsorption methods to remove radioactive cesium from contaminated water. For example, biopolymers ${ }^{5}$, nanocomposite ${ }^{6,7}$, and clay ${ }^{8}$ have all previously been investigated for their capacity to remove radioactive cesium through the interaction between the negatively charged

${ }^{1}$ Department of Biological Engineering, Biohybrid Systems Research Center (BSRC), Inha University, 100 Inha-ro, Incheon 22212, Republic of Korea. ${ }^{2}$ Biotechnology Research Division, Advanced Radiation Technology Institute (ARTI), Korea Atomic Energy Research Institute (KAERI), 29 Geumgu-gil, Jeongeup-si, Jeonbuk 56212, Republic of Korea. ${ }^{3}$ Department of Chemical Engineering, Chungnam National University, 99 Daehak-ro, Daejeon 34134, Republic of Korea. ${ }^{4}$ Department of Energy and Materials Engineering, Dongguk University-Seoul, 30 Pildong-ro 1-gil, Seoul 04620, Republic of Korea. ${ }^{5}$ Quality Management Team, Korea Institute of Energy Research (KIER), 152 Gajeong-ro, Daejeon 34129, Republic of Korea. ${ }^{6}$ Department of BioNano Technology, Gachon University, 1342 Seongnam-daero, Seongnam-si, Gyeonggi-do 13120, Republic of Korea. ${ }^{7}$ Measurement \& Analysisi Team, National Nanofab Center, 291 Daehak-ro, Daejeon 34141, Republic of Korea. ${ }^{8}$ Radiation Biotechnology and Applied Radioisotope Science, University of Science and Technology (UST), 217 Gajeong-ro, Daejeon 34113, Republic of Korea. *These authors contributed equally to this work. Correspondence and requests for materials should be addressed to C.R. (email: chroh@kaeri.re.kr) orY.S.H. (email: yunsuk.huh@inha.ac.kr) 


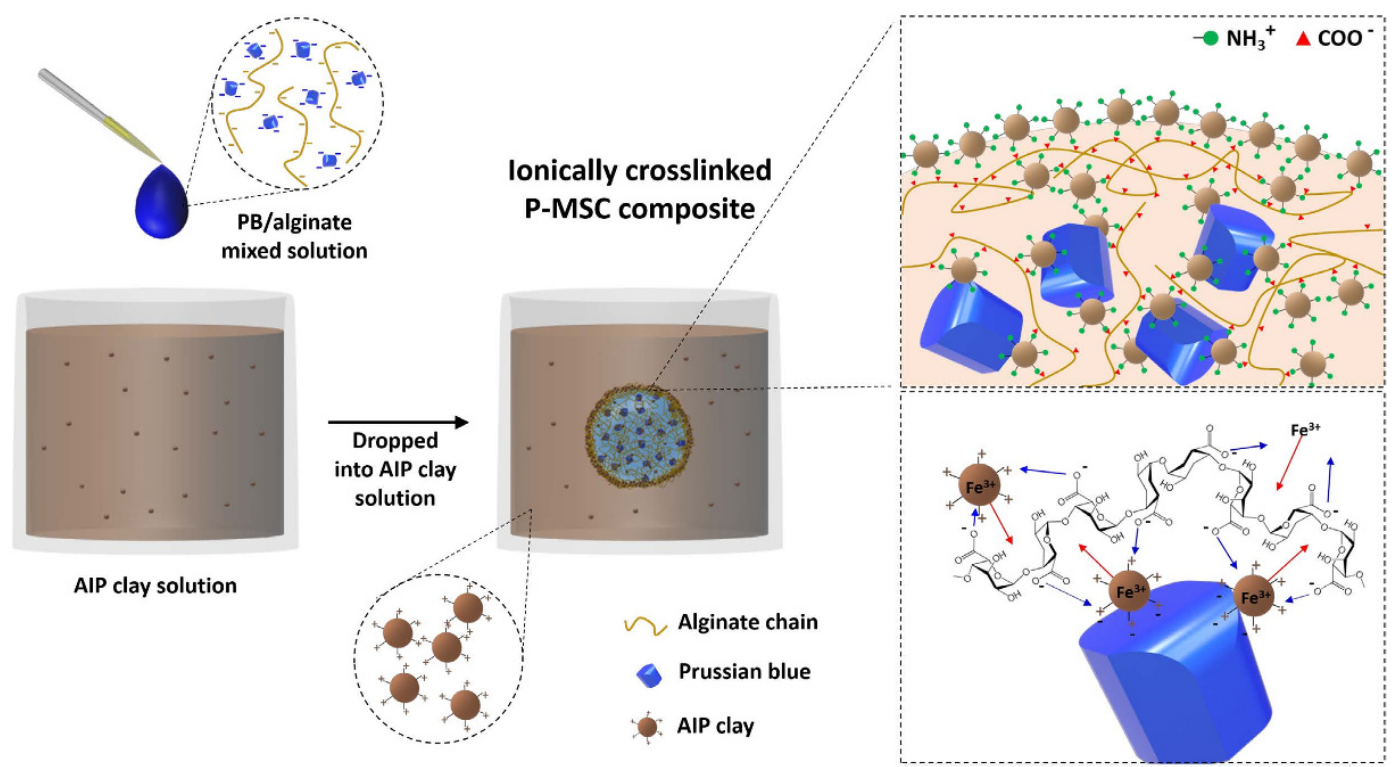

Figure 1. Schematic diagram for the fabrication of a 3D microporous PB/alginate/AIP clay composite.

surfaces of naturally occurring adsorbents and the positive charge of radioactive cesium. However, powder-type adsorbents cannot be used to treat contaminated water in a real, open environment because there is no easy way to collect the adsorbents after they are used. In particular, adsorbents can cause blocking phenomena, which could be addressed by encapsulating the adsorbents with suitable modification that could alleviate the clogging and resolve the post-treatment separation problem ${ }^{9}$. Therefore, novel solid absorbents are needed to allow easy separation of the materials from the contaminant environment to prevent secondary contamination.

Prussian blue (PB), and its analogues, is well known for its capacity for selective adsorption of radioactive cesium; hence, it has been recognized as an effective scavenger for radioactive cesium ${ }^{10,11}$. However, PB nanoparticles prepared using the precipitation method are usually a very fine powder. In water, PB nanoparticles form a stable colloidal suspension, which makes them difficult to separate from an open environment. Compositing PB with a biopolymer offers a potential solution to this problem.

Alginate has been successfully used as an eco-friendly polymer for the encapsulation of absorbing materi$\mathrm{als}^{12,13}$. Alginate, a salt of alginic acid, is a polysaccharide biopolymer derived from brown algae, and it is composed of $\beta$-1, 4-linked D-mannuronic acids, and $\alpha$-1,4-linked L-guluronic acids arranged in a chain ${ }^{14,15}$. It has carboxylic groups, which are the most frequent acidic functional group on the chain, and it has affinities for metal cations ${ }^{16}$. It has attracted much attention in many areas because of its biocompatibility, biodegradability, and rapid gelation ability. Alginate gelation occurs when multivalent cations, such as $\mathrm{Ca}^{2+}, \mathrm{Fe}^{3+}, \mathrm{Al}^{3+}$, and $\mathrm{Zr}^{4+}$, interact with blocks of guluronic residues, diffusing into the sodium alginate solution and replacing $\mathrm{Na}^{+}$. This results in the rapid formation of alginate gel ${ }^{17}$. Although alginate hydrogels have been extensively studied for adsorption applications, their use has been restricted by their poor mechanical properties and low adsorption capacities ${ }^{5,18,19}$. Especially in a marine environment treatment process, the calcium ions are easily detached by chelating agents and monovalent ions, such as $\mathrm{Na}^{+}$and $\mathrm{K}^{+}$, that are found in seawater, which results in destabilization of the alginate matrix ${ }^{20}$.

This study aimed to design and synthesize a new microporous three-dimensional (3D) network composite composed of PB encapsulated by alginate beads, which were reinforced by cross-linking aminopropyl-functionalized iron phyllosilicates (AIP) clay, for high adsorption and easy separation of radioactive cesium from contaminated water. The synthesized composite was confirmed by Fourier-transform infrared spectroscopy (FTIR), X-ray diffraction (XRD), X-ray photoelectron spectroscopy (XPS), thermal gravimetric analysis (TGA), and scanning electron microscopy (SEM). The results revealed that the composite adsorbent was highly efficient in the removal of radioactive cesium because of the good ion-exchange property of $\mathrm{PB}$ and the excellent adsorption property of the alginate/AIP clay network. Owing to the bio-compatible nature of alginate and AIP clay $^{5}$, they may form a potential class of adsorbents for environmental remediation when fabricated suitably.

\section{Results and Discussion}

Synthesis of composite. The schematic diagram for the synthesis of the AIP clay immobilized PB/alginate composite is shown in Fig. 1. The composite was fabricated using a two-step process. In the first step, PB nanoparticles dispersed in alginate solution and AIP clay dispersed in aqueous solution were prepared separately. In the second step, the $\mathrm{PB}$ /alginate solution was added drop-wise to the AIP clay solution and the solution underwent gelation for one day to form the $3 \mathrm{D}$ microporous $\mathrm{PB} /$ alginate/AIP clay composite. Alginate, AIP clay, and PB nanoparticles have different charges, with zeta potential values of $-33.34 \mathrm{mV}, 41.36 \mathrm{mV}$, and $-33.84 \mathrm{mV}$, respectively. When $\mathrm{PB} /$ alginate is added to the AIP clay solution, the $\mathrm{Fe}^{3+}$ ions of the AIP clay (Figure S2) bind to the carboxyl $\left(\mathrm{COO}^{-}\right)$groups of alginate more strongly than $\mathrm{Ca}^{2+21,22}$. This is because the relative binding affinity of 
(a)

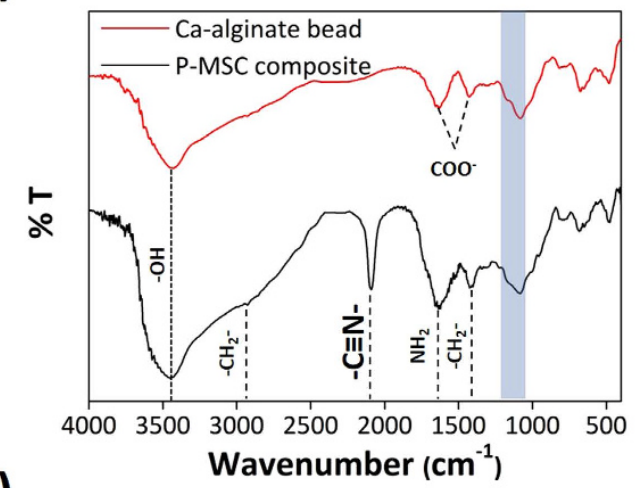

(c)

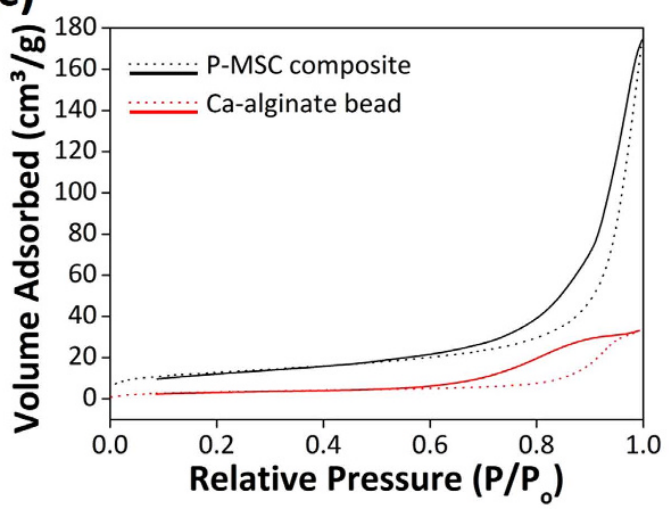

(b)

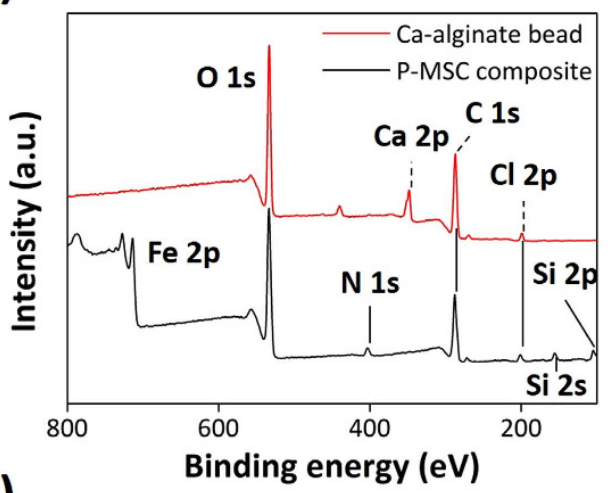

(d)

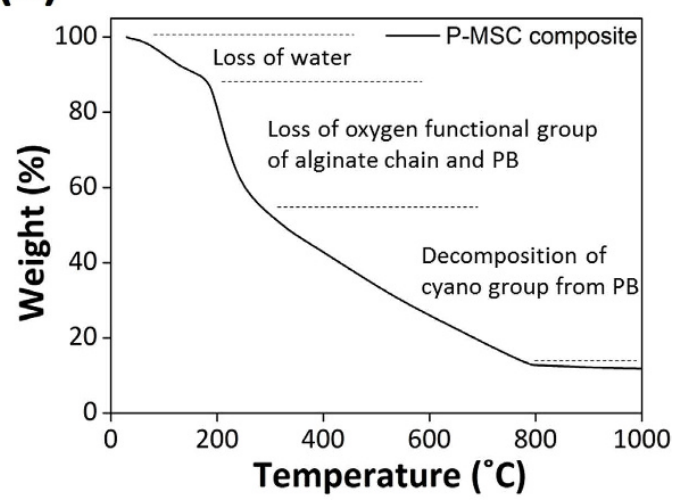

Figure 2. Characterization of Ca-alginate bead and P-MSC composite. (a) FT-IR spectra, (b) XPS spectra, and (c) the $\mathrm{BJH} \mathrm{N}_{2}$ adsorption/desorption isotherms for Ca-alginate bead and P-MSC composite, and (d) TGA curve of the P-MSC composite.

the carboxyl group to metal ion is in the order of $\mathrm{Fe}^{3+}>>\mathrm{Ca}^{2+}>>\mathrm{Na}^{+}$. On the other hand, the amino $\left(-\mathrm{NH}_{2}\right)$ groups of the AIP clay can cross-link with $\mathrm{PB}$ and alginate to form a hydrogel via ionic interactions ${ }^{23}$. Moreover, the AIP clay acts as an immobilization agent, and it can directly immobilize onto the PB/alginate matrix without forming any intermediate material. This technique allows for the direct solidification of $\mathrm{PB} /$ alginate without the need of $\mathrm{Ca}^{2+}$. The positive and negative charges of clay and alginate lead to an effective ionic interaction, which creates a porous network. This mechanism is mainly induced by the unique structure and elegant performance of the composite. In comparison to pristine Ca-alginate, the composite combines the intrinsic physical and chemical properties of the organic and inorganic materials, acquires more degrees of freedom to manipulate multiple interactions, creates hierarchical structures, and integrates multiple functionalities ${ }^{24-26}$.

Structural, morphological, and surface studies. Figure 2a illustrates the FT-IR spectra of Ca-alginate and the P-MSC composite. The FT-IR spectrum of Ca-alginate showed a broad band at $3447 \mathrm{~cm}^{-1}$ corresponding to the $-\mathrm{OH}$ stretching vibrations, and a small band at $2930 \mathrm{~cm}^{-1}$ that was due to the $\mathrm{C}-\mathrm{H}$ stretching vibrations. The bands at $1637 \mathrm{~cm}^{-1}$ and $1430 \mathrm{~cm}^{-1}$ were related to the asymmetric and symmetric stretching vibrations of the -COO groups, respectively. The broad band at $1200-1000 \mathrm{~cm}^{-1}$ corresponds to the $\mathrm{C}-\mathrm{O}-\mathrm{C}$ stretching vibrations of the carbohydrate rings ${ }^{27}$. For the alginate/AIP clay composite (Figure S1a) and P-MSC composite (Fig. 2a), in addition to the alginate bands, characteristic bands for the AIP clay (-OH stretching at $3444 \mathrm{~cm}^{-1},-\mathrm{NH}_{2}$ stretching at $1623 \mathrm{~cm}^{-1},-\mathrm{CH}_{2}$ stretching at $1425 \mathrm{~cm}^{-1}$, Si-O-Si stretching at $1035 \mathrm{~cm}^{-1}$, and Fe-O stretching at $\left.685 \mathrm{~cm}^{-1}\right)^{28}$ were observed. Particularly, the P-MSC composite showed a $-\mathrm{C} \equiv \mathrm{N}$ - stretching at $2091 \mathrm{~cm}^{-1} \mathrm{cor}^{-}$ responding to the $\mathrm{PB}$ nanoparticles ${ }^{6,29}$. These bands provide evidence for the presence of alginate, $\mathrm{PB}$, and AIP clay in the P-MSC composite. Figure $2 \mathrm{~b}$ shows the survey spectra for $\mathrm{Ca}$-alginate bead and the composite. The sharp peaks in the full scan spectra of Ca-alginate bead revealed the presence of C $1 \mathrm{~s}$ (286.58), O $1 \mathrm{~s}$ (532.48), and Ca $2 \mathrm{p}$ (348.08), whereas the full scan spectra of alginate/AIP clay composite (Figure S1b) and the P-MSC composite showed C $1 \mathrm{~s}$ (288.28), O $1 \mathrm{~s}$ (534.08), Fe 2p (713.68 eV), Si $2 \mathrm{~s}(155.08 \mathrm{eV})$, Si 2p (105.48 eV), and $\mathrm{N} 1 \mathrm{~s}(400 \mathrm{eV})$ peaks, confirming the successful immobilization of the AIP clay over the alginate matrix. The NMR spectroscopic response can be used as a local probe to extract structural information, as the chemical shift of the observed nucleus is very dependent on its environment. ${ }^{1} \mathrm{H}$ MAS NMR and ${ }^{13} \mathrm{C}$ MAS NMR spectra of Alginate, AIP clay, and P-MSC composite are shown in Figure S1c and S1d. No significant changes in the ${ }^{1} \mathrm{H}$ MAS NMR spectra, indicating a certain stability and homogeneity of the obtained materials. The carboxyl group of sodium alginate reacted ionically with the amino group and Fe ion of AIP clay during complexation. However, in ${ }^{13} \mathrm{C}$ MAS NMR spectrum of P-MSC composite observed peaks between 50-100 ppm and 150-200 ppm were assigned to $\mathrm{PB}$. The $\mathrm{PB}$ analogues are three-dimensional inorganic solids with apparently simple composition 

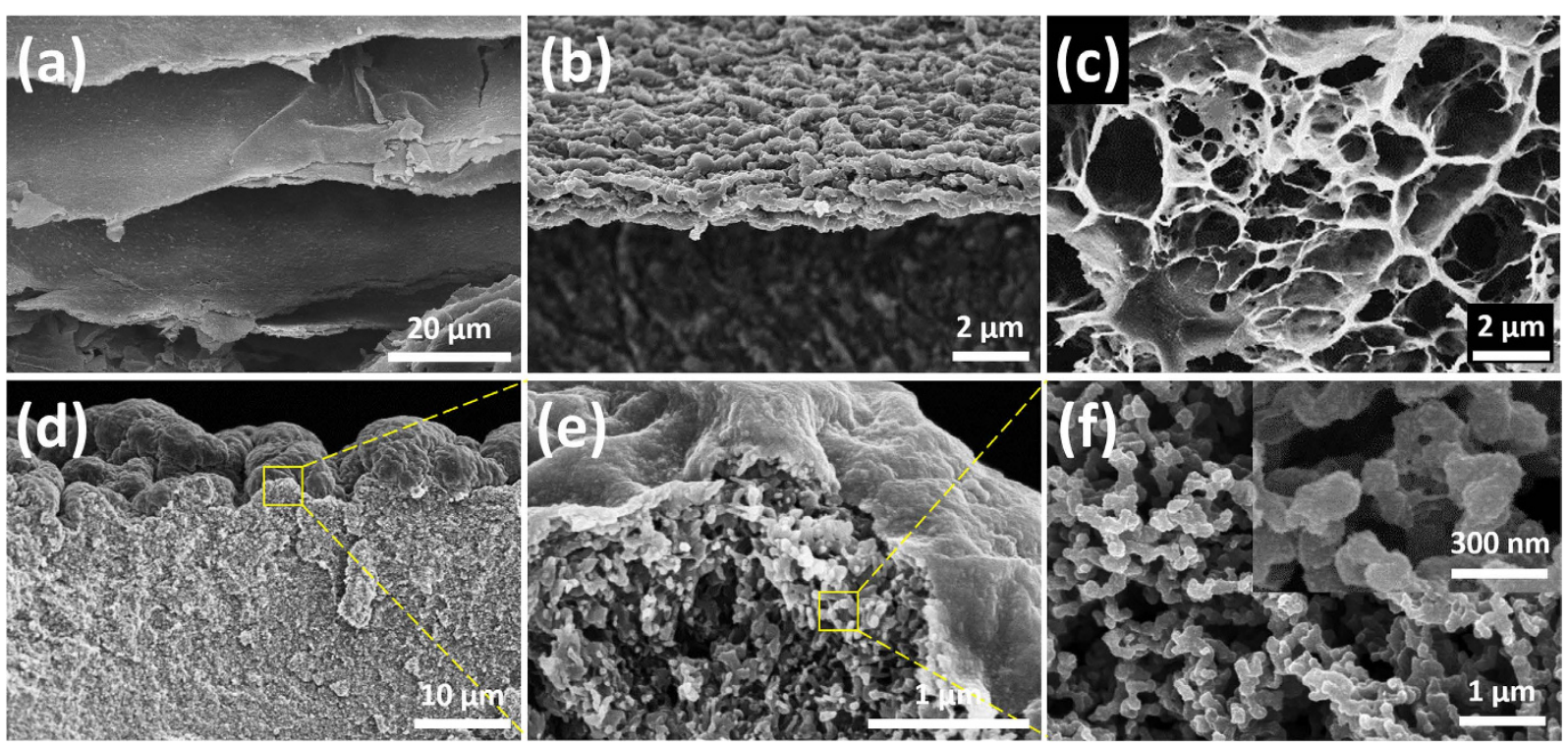

Figure 3. A cryo-fractured cross-section SEM images of (a,b) Ca-alginate, (c) alginate/AIP clay composite, and (d) P-MSC composite, (e) a magnified image of outer surface and inner structure of the P-MSC composite, and (f) close inspection of inner structure of the P-MSC composite.

(cyanide ligands connecting metal ions) and structure (cubic) cover a large family of (often nonstoichiometric) compounds (Figure S5b). These results confirmed that the AIP clay can cross-linked with PB and alginate to form a hydrogel via ionic interactions. The Brunauer-Emmett-Teller (BET) surface area of the composite (Fig. 2c) was calculated to be $44.5 \mathrm{~m}^{2} / \mathrm{g}$, which was evaluated from the $0.1<\mathrm{P} / \mathrm{P}_{0}<1.0$ region of the adsorption curve. The Barrett-Joyner-Halenda pore size distribution suggested the mesoporous nature of the composite, and the average pore diameter and pore volume were observed to be $31.34 \mathrm{~nm}$ and $0.3656 \mathrm{~cm}^{3} / \mathrm{g}$, respectively. Figure $2 \mathrm{~d}$ illustrates the TGA curve of the composite at a heating rate of $10^{\circ} \mathrm{C} / \mathrm{min}$ under nitrogen. TGA data showed a mass loss on heating even below $200^{\circ} \mathrm{C}$, probably due to the loss of water. A gradual mass loss in P-MSC composite around $300^{\circ} \mathrm{C}$ were observed with an increase in temperature, which could be attributed to the removal of coordinating water from $\mathrm{PB}$ and oxygen functional groups from alginate chain. Between 400 and $750{ }^{\circ} \mathrm{C}$, the composite showed a more obvious mass loss, which corresponded to the decomposition of the cyano group ${ }^{30,31}$. The degradation over $700^{\circ} \mathrm{C}$ was attributed to the combustion of alginate chain. When the temperature increased to $950^{\circ} \mathrm{C}$, reduction in the weight of P-MSC composite was observed due to the pyrolysis of the carbon skeleton. Figure S3 displays XRD patterns of the Ca-alginate bead, Alginate/AIP clay composite, and P-MSC composite. The diffraction peaks of Ca-alginate bead and Alginate/AIP clay composite recorded patterns which confirm their amorphous nature. Generally, the diffraction pattern of the investigated physical mixture was corresponded to the superposition of those of its individual components and revealed that Prussian blue was present, as evidenced by the presence of its diffraction lines. In the XRD spectrum of the composite, all the peaks were assigned to PB. The diffraction peaks were observed at $2 \theta=17.4^{\circ}, 24.8^{\circ}, 35.3^{\circ}$, and $39.5^{\circ}$, which were indexed to (200), (220), (222), and (400) reflections, respectively, of the face-centered cubic structure of the $\mathrm{PB}$ nanoparticles ${ }^{32}$.

Figure 3 displays the typical SEM images of Ca-alginate, the alginate/AIP clay composite and the PB/alginate/ AIP clay composite. It is clear that the Ca-alginate (Fig. 3a and b) surface was rough and porous (Figure S4a), but it possessed poor mechanical property. However, after alginate was cross-linked with the AIP clay, the material showed a microporous $3 \mathrm{D}$ network (Fig. $3 \mathrm{c}$ and S4b). Porosity can be correlated to the mechanical performance and adsorption capacity of a matrix; in our case, the adsorption capacity is anticipated for the alginate/AIP clay composite because of the porous structure. The SEM images of PB/alginate/AIP clay composite with different magnifications are shown in Fig. 3d and e. Figure 3d illustrates that the AIP clay nanoparticles were closely packed on the surface of the PB/alginate matrix. Figure 3e showed a pomegranate-like micro-scavenger cage (P-MSC) structure of the composite in which the AIP clay particles were cross-linked with the PB/alginate matrix. Close inspection of the composite (Fig. 3f) clearly showed that the AIP clay nanoparticles, with an average particle size ranging from $30-50 \mathrm{~nm}$ (Figure S5a) ${ }^{33-35}$, were immobilized onto the PB/alginate matrix. EDX analysis confirmed the elemental composition of the composites. Owning to the limited depth of EDX (a few microns), EDX result cannot reflect the full information of elemental distributions of an entire composite (size in the order of millimeters). Therefore scans of the surface (Figure S6b, d) and zoom-in of the cross section of a composite (Figure S6a,c,e) were done. Carbon peaks observed in both the spectra were predominantly from the alginate matrix, while peaks of $\mathrm{Si}$ and Fe were from AIP clay. The atomic weight percentage of $\mathrm{N}$ in the cross-section part (inner area) was higher than that of out surface. The result indicated that the elemental $\mathrm{N}$ was from Prussian blue nanoparticle. In addition, we measured SEM-EDX mapping data of the P-MSC composite (Figure S7). The SEM-EDX mapping images showed that $\mathrm{PB}$ nanoparticles were homogeneously embedded in the alginate/AIP clay composite regardless of the loading. A uniform distribution of $\mathrm{C}, \mathrm{O}, \mathrm{Si}, \mathrm{Fe}$, and $\mathrm{N}$ from alginate chain, AIP 
(a)

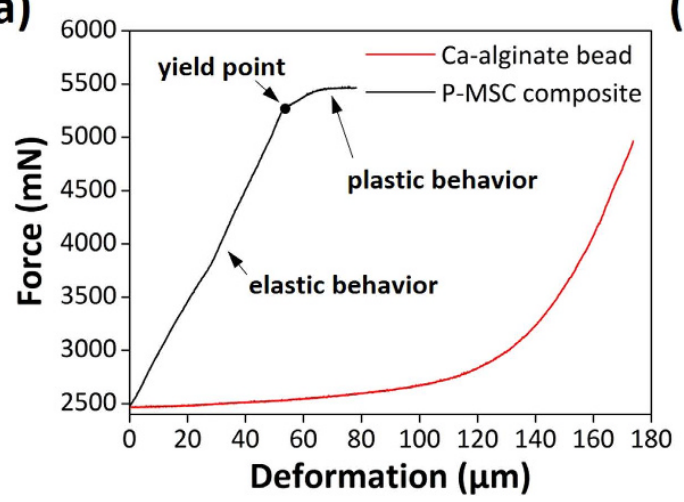

(b)

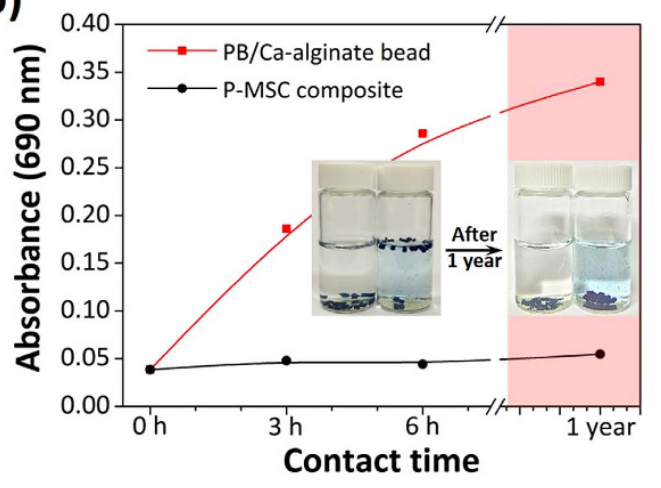

Figure 4. (a) Mechanical properties of Ca-alginate bead and P-MSC composite and (b) release behavior of PB from the $\mathrm{PB} / \mathrm{Ca}$-alginate bead and $\mathrm{P}-\mathrm{MSC}$ composite (Fig. $4 \mathrm{~b}$ inset shows the long-term study on stability of $\mathrm{PB}$ in the P-MSC composite solution during 1 year).

clay, and PB nanoparticles were observed in the composite. Additionally, the stability of materials in the colloidal system was investigated using zeta potential (Table S1). The zeta potential values of alginate, AIP clay, and Prussian blue in neutral $\mathrm{pH}$ were $-33.34 \mathrm{mV},+41.36 \mathrm{mV}$, and $-33.34 \mathrm{mV}$, respectively.

We estimated the PB content in the P-MSC composite using an ultraviolet-visible (UV-vis) spectroscopy. The release behavior of $\mathrm{PB}$ from P-MSC composite diluted to 3 and 4 times in pancreatin is shown in Figure S8a. The $\mathrm{P}-\mathrm{MSC}$ composite was completely degraded by the pancreatin, leading to total release of $\mathrm{PB}^{36}$. The $\mathrm{PB}$ release was evaluated by monitoring the blue fluorescence of the P-MSC composite. The strong absorption peaks at $690 \mathrm{~nm}$ for both samples indicating the PB release. Thus, a standard calibration curve of absorbance vs. PB concentration (Figure S8b) was used to determine the concentration of $\mathrm{PB}$ released. The 3 and 4 times diluted composite samples showed a PB release concentration of $0.069 \mathrm{mM}$ and $0.051 \mathrm{mM}$, respectively. According to the calibration data, we confirmed that about $4.755 \mathrm{mg}$ of PB present in the $20 \mathrm{mg}$ of P-MSC composite. Therefore, the P-MSC composite adsorbent contains $23.78 \%$ of $\mathrm{PB}$ content.

Mechanical property and stability studies. The mechanical properties of Ca-alginate and the P-MSC composite are shown in Fig. 4a. The principle of the measurement was to impose a force on the material by compression, and then to measure the corresponding force and the resulting deformation ${ }^{37}$. The $\mathrm{Ca}$-alginate was soft, and it showed a strain hardening at a deformation value greater than $100 \mu \mathrm{m}$. The composite bore considerable loads up to a deformation value of $50 \mu \mathrm{m}$ with a force of $5300 \mathrm{mN}$, and then it retained strain hardening. This behavior was attributed to the increase in the mechanical strength of the composite due the presence of the AIP clay. Additionally, nano-indentation is very suitable to check the mechanical properties of materials. Figure S9a illustrates the indentation depth vs. time curve recorded during a 100 second hold at a load of $45 \mathrm{mN}$. It was clear from the figure that gradual indenter penetrates into a bead surface under constant load. Instrumented indentation enables the determination of parameters for characterization of strength response. As a consequence, the apparent modulus and hardness decrease with time. An important question is that whether the deformations will be only delayed-reversible, or if also an irreversible creep will be present. As a result of indentation depth-time curve, there was no difference in the mechanical properties of $\mathrm{Ca}$-alginate bead and $\mathrm{PB} / \mathrm{Ca}$-alginate bead. During the course of the instrumented indentation process, a record of the depth of penetration was made, and then the area of the indent was determined using the known geometry of the indentation tip. While indenting, various parameters such as load and depth of penetration can be measured. A record of these values can be plotted on a graph to create a load-indentation depth curves. The load-indentation depth curves for the $\mathrm{Ca}$-alginate bead, $\mathrm{PB} / \mathrm{Ca}$-alginate bead, and P-MSC composite deflected to a central displacement of $5 \mu \mathrm{m}$ are shown (Figure S9b). These curves can be used to extract mechanical properties of the material ${ }^{38}$. The results showed that both Ca-alginate bead and $\mathrm{PB} / \mathrm{Ca}$-alginate bead surfaces were very smooth and weak as compared to P-MSC composite. Thus, the presence clay particles in the P-MSC composite was responsible for the increased mechanical property.

Adsorbent stability is an important factor because it is directly related to the adsorption capacity. Figure $4 \mathrm{~b}$ shows the long term stability test of the $\mathrm{PB} / \mathrm{Ca}$-alginate and $\mathrm{P}-\mathrm{MSC}$ composite measured by UV-vis spectroscopy. Ca-alginate is unstable in a physiological environment, and a rapid release of $\mathrm{PB}$ from alginate was observed. In contrast, the P-MSC composite was stable without the release of $\mathrm{PB}$. This may be attributed to the fact that the AIP clay played a significant role in protecting the release of the PB nanoparticles from the P-MSC composite by cross-linking with alginate to improve the mechanical stability. In addition, the ionic interaction between the AIP clay, alginate, and the PB nanoparticles was another factor that influenced the PB release. Figure $4 \mathrm{~b}$ inset shows the photograph of composite in solution after 1 year. There was no substantial release of $\mathrm{PB}$ from composite even after 1 year, indicating the excellent stability of the P-MSC composite. Thus, pure Ca-alginate could not be used in seawater as an adsorbent for the removal of radioactive cesium. Especially in a marine environment, $\mathrm{Ca}^{2+}$ ions are easily detached by the chelating agents and monovalent ions, such as $\mathrm{Na}^{+}$and $\mathrm{K}^{+}$, found in seawater, which results in destabilization of the alginate matrix ${ }^{20}$. Figure S10 and Figure S11 shows the amount of PB released from $\mathrm{PB} / \mathrm{Ca}$-alginate bead, $\mathrm{PB} / \mathrm{Fe}$-alginate bead, and $\mathrm{P}-\mathrm{MSC}$ composite in $\mathrm{DI}$ water and seawater. The results 


\begin{tabular}{|l|c|c|c|c|c|c|}
\hline \multirow{2}{*}{} & \multicolumn{3}{|c|}{ Langmuir model } & \multicolumn{3}{c|}{ Freundlich model } \\
\cline { 2 - 7 } & $\boldsymbol{K}_{\boldsymbol{L}}(\mathbf{L} / \mathbf{m g})$ & $\boldsymbol{q}_{\boldsymbol{m}}(\mathbf{m g} / \mathbf{g})$ & $\boldsymbol{R}^{\mathbf{2}}$ & $\boldsymbol{K}_{\boldsymbol{F}}(\mathrm{L} / \mathbf{m g})$ & $\boldsymbol{n}$ & $\boldsymbol{R}^{\mathbf{2}}$ \\
\hline Ca-alginate & 4.53 & 2.25 & 0.39 & 1.56 & 9.91 & 0.005 \\
\hline Alginate/AIP clay composite & 0.13 & 48.48 & 0.97 & 7.47 & 1.92 & 0.98 \\
\hline P-MSC composite & 0.06 & 108.06 & 0.95 & 11.1 & 1.82 & 0.99 \\
\hline
\end{tabular}

Table 1. Langmuir and Freundlich model parameters for the adsorption of cesium ion onto Ca-alginate, alginate/AIP clay composite and P-MSC composite.

indicated that the $\mathrm{PB} / \mathrm{Ca}$-alginate bead released around $11 \mathrm{mM}$ concentration of $\mathrm{PB}$ after 6 days. However, there was no substantial release of PB from the P-MSC composite. PB is composed of approximately $40 \%$ cyanide which is a toxicological concern ${ }^{39}$. The $\mathrm{PB}$ release data suggests that the P-MSC composite did not affect significantly the cyanide release. Thus, the toxicity resulting from cyanide release is not expected to be a medical concern. In this study, we successfully designed and synthesized a P-MSC composite with high stability and good mechanical property.

Adsorption isotherms. The study of adsorption isotherm is an informative way to examine adsorbent performance. Two adsorption isotherm models, the Langmuir and Freundlich models, were used to investigate cesium adsorption. The Langmuir model ${ }^{40}$ is based on the assumption that all the active sites are equivalent and independent, and it indicates a monolayer adsorption process for cesium onto the uniformly adsorbent surface. The linear and nonlinear forms of the equation are written as:

$$
\begin{gathered}
\frac{C_{e}}{q_{e}}=\frac{1}{K_{L}}+\frac{C_{e}}{q_{\text {max }}} \\
q_{e}=q_{\max } \frac{K_{L} C_{e}}{1+K_{L} C_{e}}
\end{gathered}
$$

where $q_{e}$ and $q_{\max }$ are the equilibrium adsorption capacity and monolayer maximum adsorption capacity (mg/g), respectively, and $K_{L}$ is a constant related to the affinity between the adsorbent and the adsorbate (Figure S12a).

In comparison, the Freundlich adsorption isotherm model ${ }^{41}$ is considered to be an empirical equation that describes multi-layer adsorption with several types of adsorption sites on the surface of an adsorbent. The model consists of the following equations:

$$
\begin{gathered}
\ln q_{e}=\ln K_{F}+\frac{\ln C_{e}}{n} \\
q_{e}=K_{F} C_{e}^{1 / n}
\end{gathered}
$$

where $K_{F}$ and $n$ are the Freundlich constants relative to the multilayer adsorption capacity (Figure S12a).

In this present study, the adsorption capacity of the P-MSC composite as a function of cesium concentration was investigated by varying the initial concentration of cesium from $0.5 \mathrm{ppm}$ to $50 \mathrm{ppm}$. The adsorption capacity increased rapidly with increasing cesium ion concentration when the initial concentration of cesium was less than $30 \mathrm{ppm}$, which may be attributed to the fact that sufficient active sites were available for the adsorption of cesium. At higher concentrations (above $30 \mathrm{ppm}$ ), competition for available adsorption sites could be decreased, resulting in a slower increase in the adsorption capacity. The experimental data were fitted to the Langmuir and Freundlich isotherm models. The linear regression correlation $\left(R^{2}\right)$ and constant values are listed in Table 1. For the Langmuir isotherm (Fig. 5a), a plot of $1 / C_{e}$ against $1 / q_{e}$ produced a straight line with an $R^{2}$ value of 0.95 . For the Freundlich isotherm (Fig. 5b), the plot of $\ln C_{e}$ against $\ln q_{e}$ was used to evaluate the constants $K_{F}$ and $n$ from the slope and intercept, and the constant values were calculated to be 11.1 and 1.82, respectively. The isotherm showed a good fit with the Freundlich model, with an $R^{2}$ value of 0.99 . The $n$ represents the heterogeneity factor, and it provides an indication of the favorability and capacity of the adsorption. The observed $n$ value indicates the physical adsorption of cesium ions onto the composite. It was found that the composite possessed an impressive $q_{m}$ of $108.06 \mathrm{mg} / \mathrm{g}$ for the cesium ion adsorption, which was higher than that of the Ca-alginate $(2.25 \mathrm{mg} / \mathrm{g})$ and alginate/AIP clay composite $(48.48 \mathrm{mg} / \mathrm{g})$. The result indicated that 1 unit of P-MSC composite $(364.28 \pm 17.37 \mu \mathrm{g})$ could adsorb approximately $39.4 \mu \mathrm{g}$ of cesium.

Adsorption kinetics. The adsorption kinetics were investigated via widely-used kinetic models (Figure S12b), such as pseudo first-order and second-order kinetics ${ }^{42,43}$. The adsorption mechanism and rate controlling steps, such as chemical reaction and mass transport, can be explained by first-order kinetics. The pseudo first-order rate equation can be expressed as:

$$
\frac{d q_{t}}{d t}=k_{1}\left(q_{e}-q_{t}\right)
$$


(a)

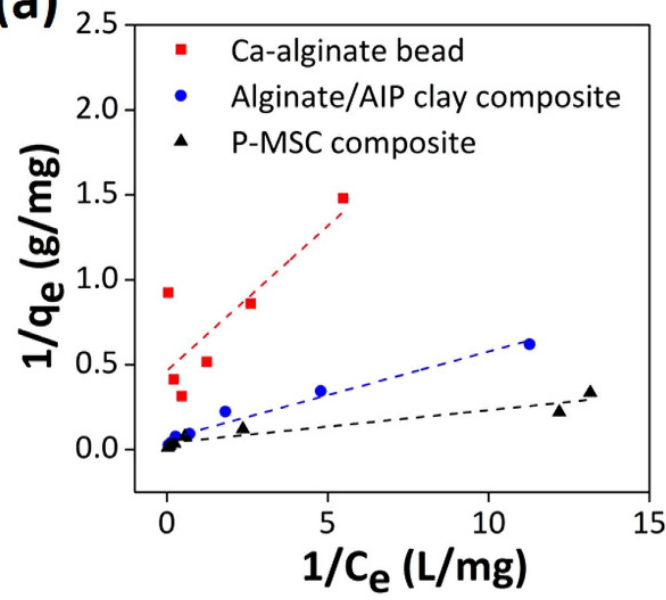

(c)

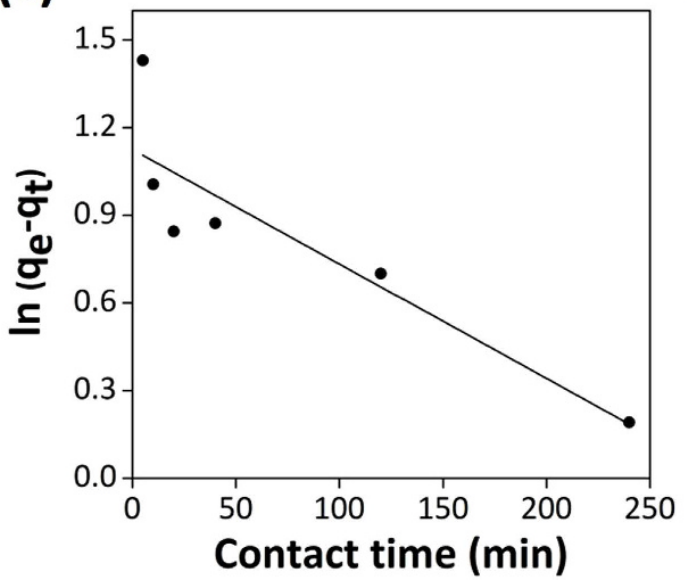

(b)

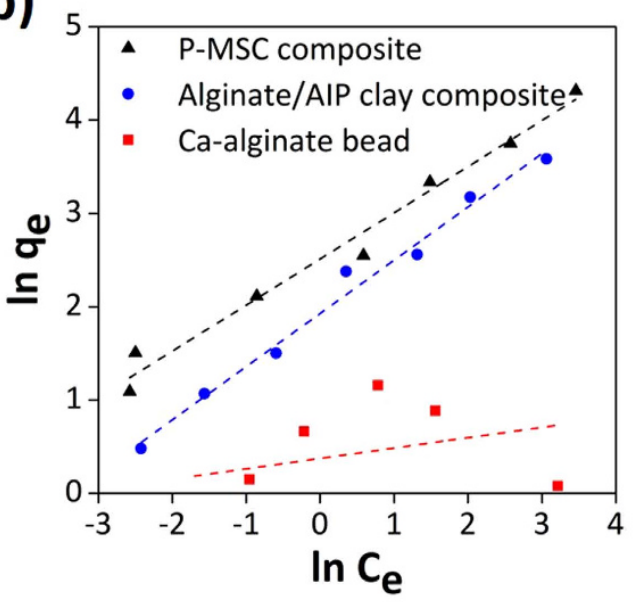

(d)

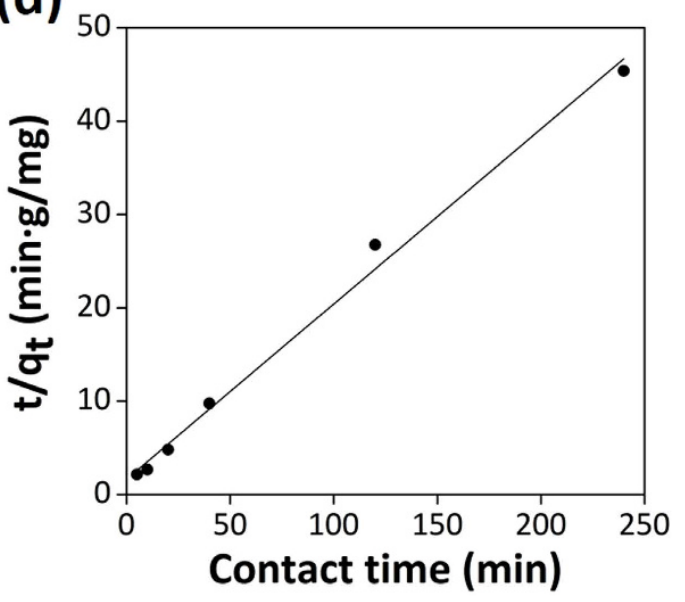

Figure 5. Adsorption isotherms and kinetics data. (a) Langmuir isotherm (b) Freundlich model, (c) pseudofirst-order, and (d) pseudo-second-order kinetics of the P-MSC composite.

where $q_{e}$ and $q_{t}$ are the adsorption capacities $(\mathrm{mg} / \mathrm{g})$ at equilibrium and at time $t$, respectively, and $k_{1}$ is the pseudo first-order rate constant $(\mathrm{g} / \mathrm{mg} \mathrm{min})$. Upon integration and after applying boundary conditions $t=0$ to $t=\mathrm{t}$ and $\mathrm{q}_{t}=0$ to $q_{t}=q_{t}$, a simplified linear form of the rate equation can be obtained:

$$
\ln \left(q_{e}-q_{t}\right)=\ln q_{e}-k_{1} t
$$

A plot of $\ln \left(q_{e}-q_{t}\right)$ versus $t$ (Fig. 5c) showed a straight line with the $R^{2}$ value of 0.75 . From the slope and intercept of the straight line, the $q_{e}$ and $k_{1}$ values were calculated as $3.08 \mathrm{mg} / \mathrm{g}$ and $0.0039 \mathrm{~g} / \mathrm{mg} \mathrm{min}$, respectively.

The second-order model is based on the assumption that the rate-limiting step may be chemisorption involving valence forces through the sharing of electrons between the adsorbent and the adsorbate as covalent forces. The second-order-rate equation can be described as follows:

$$
\begin{aligned}
& \frac{d q_{t}}{d t}=k_{2}\left(q_{e}-q_{t}\right)^{2} \\
& \frac{t}{q_{t}}=\left[\frac{1}{k_{2} q_{e}^{2}}\right]+\frac{1}{q_{e}} t
\end{aligned}
$$

The $q_{e}$ and $k_{2}$ (second-order rate constant, g/mg min) values were calculated from the linear plot of $\ln \left(q_{e}-q_{t}\right)$ versus $t$ (Fig. $5 \mathrm{~d}$ ) as $5.33 \mathrm{mg} / \mathrm{g}$ and $0.0214 \mathrm{~g} / \mathrm{mg} \mathrm{min}$, respectively. The results revealed that the second-order model provided a better fit with an $R^{2}$ value of 0.99 , implying that the adsorption rate of the composite depends on the active sites rather than the concentration of cesium in the solution. The rate-limiting step was controlled by the chemical adsorption related to the exchange of protons between PB (present in the composite) and cesium ${ }^{44}$.

Selectivity and adsorption mechanism. The cleanup of radioactive cesium is very difficult due to the lack of knowledge regarding the competition behaviors of the large number of mono- and divalent cations. The 
(a)

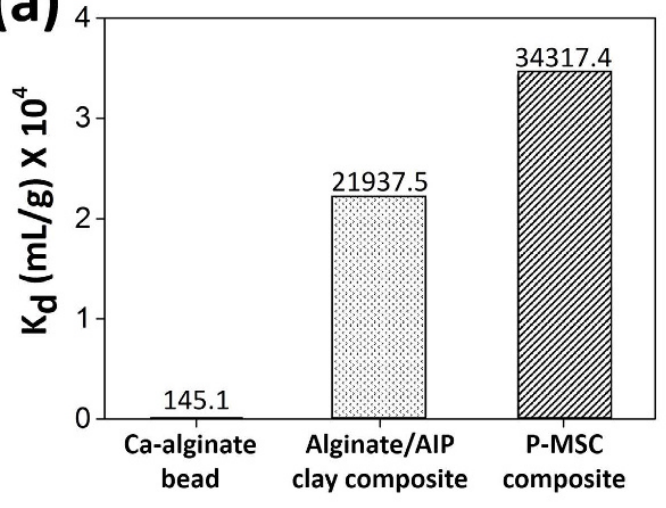

(c)

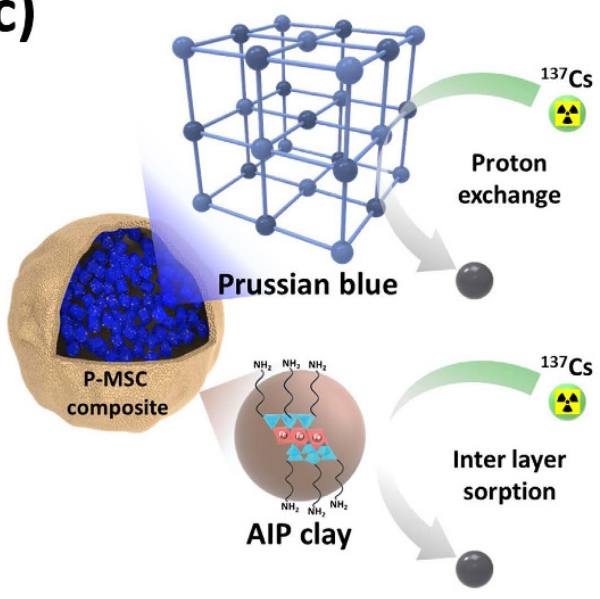

(b)
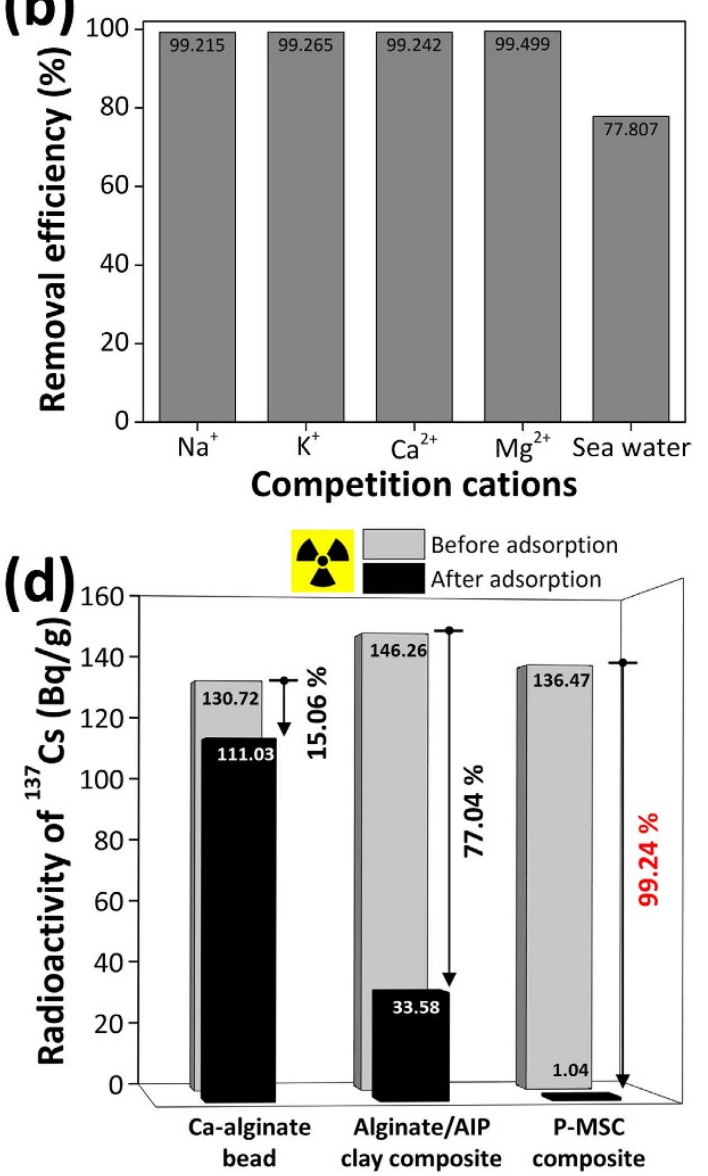

Figure 6. (a) Adsorption capacity values of the Ca-alginate, alginate/AIP clay composite, and P-MSC composite, (b) removal efficiency of cesium ion compared to competitor cations such as $\mathrm{Na}^{+}, \mathrm{K}^{+}, \mathrm{Ca}^{2+}, \mathrm{Mg}^{2+}$, and seawater (Cs concentration of $0.25 \mathrm{ppm}$ or $1.88 \times 10^{-3} \mathrm{mmol} / \mathrm{L}$ was initially spiked in all the samples, (c) adsorption mechanism, and (d) the removal efficiency of radioactive cesium using different adsorbents.

cesium adsorption capacity of Ca-alginate, the alginate/AIP clay composite, and the P-MSC composite was evaluated in terms of the distribution coefficient $\left(K_{d}\right)$. The $K_{d}$ value was defined to evaluate the ability of the adsorbent to remove the cesium ions from the contaminated water:

$$
K_{d}=\frac{C_{0}-C_{e}}{C_{e}} \times \frac{V}{M}
$$

where $C_{0}$ and $C_{e}$ represent the initial and equilibrium concentration of cesium in solution, respectively, $V$ is the volume of the cesium solution, and $M$ is the mass of the adsorbent. At a cesium concentration of $0.2 \mathrm{ppm}$, the $K_{d}$ values of Ca-alginate, alginate/AIP clay composite, and P-MSC composite were $145.1 \mathrm{~mL} / \mathrm{g}, 21,937.5 \mathrm{~mL} / \mathrm{g}$, and $34,317.4 \mathrm{~mL} / \mathrm{g}$, respectively (Fig. 6a). The resulting composite had a $K_{d}$ value that was 236 -fold higher than that of Ca-alginate. As a comparison, we also synthesized Fe-alginate bead and PB/Fe-alginate bead, and evaluated the cesium adsorption capacity. The results are shown in Figure S13. The results showed that the Fe-alginate bead $(80.9 \mathrm{~mL} / \mathrm{g})$ had a similar cesium adsorption capacity of Ca-alginate bead. The $K_{d}$ value of PB contained $\mathrm{Fe}$-alginate bead $(2,982.4 \mathrm{~mL} / \mathrm{g})$ was lower than that of Alginate/AIP clay composite and P-MSC composite. The $K_{d}$ value of P-MSC composite was 11.5-fold higher than that of the $\mathrm{PB} / \mathrm{Fe}$-alginate bead. This may be attributed to the high affinity of the PB nanoparticles towards cesium. The higher $K_{d}$ value indicated a strong binding affinity, and this value was most meaningful at dilute concentrations of the adsorbate, which is similar to a real environment. Generally, a $K_{d}$ value greater than 5,000 is considered to be good and a $K_{d}$ value higher than 50,000 is considered to be excellent ${ }^{45}$. The selectivity of P-MSC composite for cesium (Fig. 6b) was evaluated by measuring the removal efficiency of cesium in the presence of competing cations such as $\mathrm{Na}^{+}(0.25 \mathrm{ppm}), \mathrm{K}^{+}(0.25 \mathrm{ppm}), \mathrm{Ca}^{2+}$ $(0.25 \mathrm{ppm}), \mathrm{Mg}^{2+}(0.25 \mathrm{ppm})$ or real seawater contained an approximately sixteen thousand times higher concentration of competing cations than cesium concentration $(0.25 \mathrm{ppm})$. A $0.25 \mathrm{ppm}$ cesium was initially spiked in all the samples. The P-MSC composite showed excellent selectivity toward cesium ions because the concentration of cesium in any environment is significantly lower than the concentrations of co-existing cations, such as $\mathrm{K}^{+}, \mathrm{Na}^{+}, \mathrm{Ca}^{2+}$, and $\mathrm{Mg}^{2+}$. The competition ions are abundant in both fresh water and seawater. These results indicated that within the concentration of $9.4 \times 10^{-3} \mathrm{mmol} \mathrm{K}^{+}, \mathrm{Na}^{+}, \mathrm{Ca}^{2+}$, and $\mathrm{Mg}^{2+}$, the cesium ion adsorption 
capacity of the P-MSC composite remained unchanged. The divalent cations had no effect or very little effect on the cesium ion adsorption. Although the removal efficiency of the cesium ions decreased at seawater, the P-MSC composite showed excellent selectivity toward the cesium ions even in the presence of competition cations that had a concentration that was approximately thousand-times higher than cesium (Figure S14). These results can be explained by the ability of PB to selectively adsorb hydrated cesium ions. The selectivity could be caused by the regular lattice spaces surrounded by the cyanide-bridged metals and the effect of the proton-exchange mechanism on the specific cesium ion adsorption (Fig. 6c) ) $^{30,46}$. The adsorption ability of PB for alkali and alkaline earth metal ions increased in the order of $\mathrm{Cs}^{+}>>\mathrm{Na}^{+}, \mathrm{K}^{+}, \mathrm{Ca}^{2+}$, and $\mathrm{Mg}^{2+}$.

Decontamination of radioactive cesium. The efficiency percentage of the radioactive cesium removal using the P-MSC composite was calculated using the following equation:

$$
\text { Removal efficiency }(\%)=\frac{\left(C_{0}-C_{e}\right)}{C_{0}} \times 100
$$

where $C_{0}$ and $C_{e}$ represent the initial and equilibrium concentrations of the cesium solution, respectively. Figure $6 \mathrm{~d}$ shows the removal efficiency of radioactive cesium using Ca-alginate, the alginate/AIP composite, and the P-MSC composite. The adsorbents $(1.0 \mathrm{mg} / \mathrm{mL}$, each) were added to the radioactive cesium solutions (approximately $130 \mathrm{~Bq} / \mathrm{g}$ ) and agitated for $12 \mathrm{~h}$. The adsorbents were then separated from the solutions by filtration through a syringe filter, after which the solutions were analyzed to determine the radioactive cesium concentration. The radioactive cesium removal efficiency reached $77.04 \%$ using the alginate/AIP composite, which was attributed to the large number of adsorption sites on the AIP clay. Further encapsulation of the PB nanoparticles in the adsorbent enhanced the removal efficiency up to $99.24 \%$. Thus, the high removal efficiency further confirmed the potential application of the P-MSC composite for decontamination of water containing radioactive cesium.

\section{Conclusions}

We successfully fabricated a 3D microporous composite by immobilization of AIP clay onto the PB/alginate matrix (i.e., ionic interaction between the AIP clay and the PB/alginate matrix) for selective adsorption of cesium ions from seawater. Pomegranate-like cage structured PB/alginate/AIP clay composite was confirmed by microscopy analysis. The adsorption results revealed that the composite showed a radioactive cesium removal efficiency of $99.24 \%$. This may be attributed to the 3D porous network structure of the alginate/AIP clay and the good ion-exchange property of the PB. Experimental results demonstrated that the adsorption was in accordance with the Freundlish isotherm and consistent with second-order kinetics. It is anticipated that the P-MSC composite presents a new class of an environmentally-friendly adsorbent for the removal of radioactive cesium, which has been limited by natural clay or polymer-modified clays.

\section{Methods}

Materials. 3-aminopropyltriethoxysilane (denoted APTES, $\geq 98 \%$ ), iron (III) chloride, sodium alginate, Prussian blue (PB), and calcium chloride $\left(\mathrm{CaCl}_{2}\right)$ were purchased from Sigma-Aldrich (USA) and used without further purification. The inactive cesium solution and radioactive cesium $\left({ }^{137} \mathrm{Cs}\right)$ were obtained from Kanto Chemical Co. Inc. and Korea Atomic Energy Research Institute (KAERI), respectively. Seawater was obtained from the coastal sea area of Incheon, Korea.

Preparation of AIP clay. The 3-Aminopropyl-functionalized iron phyllosilicate was synthesized as previously described ${ }^{33,35,47}$. In brief, the solution was prepared with $\mathrm{FeCl}_{3} \cdot 6 \mathrm{H}_{2} \mathrm{O}(41.32 \mathrm{mmol}, 8.4 \mathrm{~g})$, which was dissolved in $200 \mathrm{~mL}$ of ethanol in a $500 \mathrm{~mL}$ beaker by stirring for $10 \mathrm{~min}$. Then, 3 -aminopropyltriethoxysilane $(58.73 \mathrm{mmol}, 13 \mathrm{~mL})$ was added and adjusted to a molar ratio $\left(\mathrm{FeCl}_{3} \cdot 6 \mathrm{H}_{2} \mathrm{O}\right.$ to $\left.\mathrm{C}_{9} \mathrm{H}_{23} \mathrm{NO}_{3} \mathrm{Si}\right)$ of 7:10. After mixing for about $5 \mathrm{~min}$, a brown slurry was formed. To ensure sufficient equilibrium time for the AIP clay production, the reaction was continued overnight. The precipitated AIP clay was centrifuged at $6000 \mathrm{rpm}$ for $10 \mathrm{~min}$, and the pelleted material was washed twice with $200 \mathrm{~mL}$ ethanol by repeated centrifugation. The product was dried in an oven at $50^{\circ} \mathrm{C}$ for $24 \mathrm{~h}$. Prior to use, the AIP clay was powdered using a pestle and mortar. The unit structure of the clay $\left(\left[\mathrm{H}_{2} \mathrm{~N}\left(\mathrm{CH}_{2}\right)_{3}\right]_{8} \mathrm{Si}_{8} \mathrm{Fe}_{6} \mathrm{O}_{12}(\mathrm{OH})_{4}\right)$ contains a central octahedral brucite-like $\mathrm{Fe}(\mathrm{OH})_{2}$ in which the top and bottom are overlaid with tetrahedral silica ${ }^{48}$, followed by capping with vertical layers of flexible $-\left(\mathrm{CH}_{2}\right)_{3} \mathrm{NH}_{2}$ group ${ }^{49}$. Clay is easily prepared at room temperature via a sol-gel process using iron chloride and organotrialkoxysilane as precursors ${ }^{50}$. AIP clay has emerged as a new class of organic-inorganic layered materials that are derivatives of 2:1 trioctahedral iron phyllosilicates covalently bonded with aminopropyl moieties occupying the interlayer regions ${ }^{51}$. Supplementary Fig. S2 shows the structure of the AIP clay.

Synthesis of Ca-alginate beads. Using a typical fabrication method, the $\mathrm{CaCl}_{2}$ flakes $(0.2 \mathrm{~g})$ were dissolved in deionized (DI) water $(10 \mathrm{~mL})$ by stirring for $1 \mathrm{~h}$. Aqueous sodium alginate in DI water $(10 \mathrm{~mL}, 2 \mathrm{wt} \%)$ was prepared separately, and then the alginate solution was added drop-wise into the $\mathrm{CaCl}_{2}$ solution. The hydrogel was shaken for $1 \mathrm{~h}$, and then left to stand for $24 \mathrm{~h}$. After collection, the hydrogel beads were immediately washed with DI water and freeze dried.

Synthesis of the alginate/AIP clay composite. The alginate solution was prepared by dissolving $2 \mathrm{wt} \%$ sodium alginate in DI water. The AIP clay solution was prepared by dispersing $1.5 \mathrm{~g}$ of AIP clay nanoparticles in $30 \mathrm{~mL}$ DI water. Due to the intrinsic use of ferric ions in AIP clay synthesis, the clay was a brown color. The 
alginate solution was dropped into the AIP clay solution. The hydrogel was shaken for $1 \mathrm{~h}$, and then it was left to stand for $24 \mathrm{~h}$. After collection, the hydrogel beads were washed with DI water and freeze dried.

Synthesis of the P-MSC composite. The P-MSC composite was fabricated using a similar procedure described for synthesis of the alginate/AIP clay composite. However, instead of the alginate solution, $50 \mu \mathrm{L}$ of PB nanoparticles suspension $(1 \mathrm{M})$ containing alginate solution $(2 \%, 10 \mathrm{~mL})$ was used.

Characterization of the Ca-alginate beads, MSCs and P-MSCs. The SEM images were acquired using an S-4800SE microscope at an acceleration voltage of $15 \mathrm{kV}$. The FTIR spectra were recorded using a Jasco FT/IR-6600. The XRD patterns were collected using a Bruker D2 PHASER (Germany) diffractometer with Cu $\mathrm{K} \alpha$ radiation. The BET surface area and average pore diameter were obtained from the $\mathrm{N}_{2}$ adsorption/desorption isotherm using a fully automatic physisorption analyzer (ASAP 2020, Tristar). The XPS measurements were obtained using a Thermo Scientific, K-Alpha electron spectrometer with an Al X-ray source. UV-vis analysis were carried out using a V770 (JASCO) spectrophotometer. The mechanical properties were measured using micro-indenter measurements (Noise Is a Signal (NIS), customized). The inductively coupled plasma mass spectrometry (ICP-ms) measurements were carried out using a PerkinElmer ELAN6100. The radioactive cesium activity was measured using a High Purity Germanium (HPGe) detector (Canberra, USA).

Zeta potential experiment. The zeta-potential values of the alginate, clay, and PB nanoparticle were measured in a Zeta-potential \& Particle size Analyzer ELSZ (Ousuka, Japan). In most cases, colloidal particles possess a positive or negative electrostatic charge. As electrical fields are applied to the particle dispersion, the particles migrate in oppositely charged directions. As particles are irradiated in migration, scattering light causes Doppler shift depending on electrophoretic mobility. This method is called Laser Doppler Method. The essence of a classical micro-electrophoresis system is a cell with electrodes at either end to which a potential is applied. Particles move toward the electrode of opposite charge, and their velocity is measured. This velocity expressed per unit field strength is considered as its electrophoretic mobility of the particles. With this knowledge we can estimate the zeta-potential of the particles.

The PB release behavior from the composite materials. The $\mathrm{PB} / \mathrm{Ca}$-alginate and $\mathrm{P}-\mathrm{MSC}$ composites (each $10 \mathrm{mg}$ ) were separately immersed in DI water at room temperature for $6 \mathrm{~h}$ and shaken with a rotary shaker. The PB release behavior from the composite materials was evaluated by UV-vis spectroscopy at $690 \mathrm{~nm}$.

Adsorption isotherms. The adsorption isotherms were investigated based on batch experiments. Inactive cesium was used to study the adsorption behavior. The initial cesium concentration varied from $0.5 \mathrm{ppm}$ to $50 \mathrm{ppm}$. A total of $10 \mathrm{mg}$ of the adsorbent was added to $4 \mathrm{~mL}$ of the aqueous cesium solution. The test tube was then shaken at $60 \mathrm{rpm}$ using a rotary shaker for $12 \mathrm{~h}$. After reaching equilibrium, the adsorbent was separated by filtration, and the residual cesium concentration was analyzed using ICP-ms.

Adsorption kinetics. For the kinetic studies, the sample was prepared by dispersing $20 \mathrm{mg}$ of the P-MSC composite in $10 \mathrm{ppm}$ of the cesium solution $(10 \mathrm{ml})$ on a shaker at $200 \mathrm{rpm}$. The samples were taken at $5,10,20$, $40,90,120$, and $240 \mathrm{~min}$

Selectivity experiment. Selectivity experiments were carried out using $5 \mathrm{~mL}$ of the cesium solution $\left(0.25 \mathrm{ppm}, 1.88 \times 10^{-3} \mathrm{mmol} / \mathrm{L}\right)$ containing $10 \mathrm{mg}$ of the P-MSC composite. After $12 \mathrm{~h}$ of agitation, the aqueous solution was removed and filtered through a syringe filter. The initial and residual cesium concentrations were analyzed using ICP-ms.

Decontamination of radioactive cesium. The solution containing radioactive cesium was prepared by diluting a stock solution to approximately $130 \mathrm{~Bq} / \mathrm{g}$. The required amount of adsorbent $(10 \mathrm{mg})$ was dispersed in $10 \mathrm{~mL}$ of the radioactive cesium solution, after which the vial was shaken for $12 \mathrm{~h}$. Next, the aqueous solution was filtered through a syringe filter, and the adsorption capacity was measured using the HPGe detector (Canberra, USA).

\section{References}

1. Buesseler, K., Aoyama, M. \& Fukasawa, M. Impacts of the Fukushima nuclear power plants on marine radioactivity. Environ. Sci. Technol. 45, 9931-9935 (2011).

2. Brumfiel, G. Fukushima set for epic clean-up. Nature 472, 146-147 (2011).

3. Yasunari, T. J. et al. Cesium-137 deposition and contamination of Japanese soils due to the Fukushima nuclear accident. Proc. Natl. Acad. Sci. USA 108, 19530-19534 (2011).

4. Bandazhevsky, Y. I. Radioactive cesium and the heart: pathophysiological aspects. The Belrad Institute, 1-59 (2001).

5. Vipin, A. K., Hu, B. \& Fugetsu, B. Prussian blue caged in alginate/calcium beads as adsorbents for removal of cesium ions from contaminated water. J. Hazard. Mater. 258, 93-101 (2013).

6. Jang, S.-C. et al. Porous three-dimensional graphene foam/Prussian blue composite for efficient removal of radioactive ${ }^{137} \mathrm{Cs}$. Sci. Rep. 5, 17510 (2015).

7. Yang, H.-M. et al. Prussian blue-functionalized magnetic nanoclusters for the removal of radioactive cesium from water. J. Alloy. Compd. 657, 387-393 (2016).

8. Bostick, B. C., Vairavamurthy, M. A., Karthikeyan, K. \& Chorover, J. Cesium adsorption on clay minerals: An EXAFS spectroscopic investigation. Environ. Sci. Technol. 36, 2670-2676 (2002).

9. Tan, W. S. \& Ting, A. S. Y. Alginate-immobilized bentonite clay: Adsorption efficacy and reusability for Cu (II) removal from aqueous solution. Bioresour. Technol. 160, 115-118 (2014).

10. Fujita, H., Sasano, H., Miyajima, R. \& Sakoda, A. Adsorption equilibrium and kinetics of cesium onto insoluble Prussian blue synthesized by an immediate precipitation reaction between $\mathrm{Fe}^{3+}$ and $\left[\mathrm{Fe}(\mathrm{CN})_{6}\right]^{4-}$. Adsorption 20, 905-915 (2014).

11. Parajuli, D. et al. Comparative study of the factors associated with the application of metal hexacyanoferrates for environmental Cs decontamination. Chem. Eng. J. 283, 1322-1328 (2016). 
12. Lim, S.-F., Zheng, Y.-M., Zou, S.-W. \& Chen, J. P. Characterization of copper adsorption onto an alginate encapsulated magnetic sorbent by a combined FT-IR, XPS, and mathematical modeling study. Environ. Sci. Technol. 42, 2551-2556 (2008).

13. Mahmoodi, N. M. Equilibrium, kinetics, and thermodynamics of dye removal using alginate in binary systems. J. Chem. Eng. Data 56, 2802-2811 (2011).

14. Haug, A., Larsen, B. \& Smidsrod, O. Studies on the sequence of uronic acid residues in alginic acid. Acta Chem. Scand. 21, 691-704 (1967).

15. Jin, Z. et al. Electrochemically controlled drug-mimicking protein release from iron-alginate thin-films associated with an electrode. ACS Appl. Mater. 4, 466-475 (2012).

16. Kang, D. et al. "Egg-Box"-assisted fabrication of porous carbon with small mesopores for high-rate electric double layer capacitors. ACS nano 9, 11225-11233 (2015).

17. Qiusheng, Z., Xiaoyan, L., Jin, Q., Jing, W. \& Xuegang, L. Porous zirconium alginate beads adsorbent for fluoride adsorption from aqueous solutions. RSC Adv. 5, 2100-2112 (2015).

18. Mihara, Y. et al. Adsorption kinetic model of alginate gel beads synthesized micro particle-prussian blue to remove cesium ions from water. J. Water Process Eng. 10, 9-19 (2016).

19. Lai, Y.-C. et al. Poly (vinyl alcohol) and alginate cross-linked matrix with immobilized Prussian blue and ion exchange resin for cesium removal from waters. Bioresour. Technol. 214, 192-198 (2016).

20. Pannier, A., Soltmann, U., Soltmann, B., Altenburger, R. \& Schmitt-Jansen, M. Alginate/silica hybrid materials for immobilization of green microalgae Chlorella vulgaris for cell-based sensor arrays. J. Mater. Chem. B 2, 7896-7909 (2014).

21. Hong, L. \& Simon, J. D. Current understanding of the binding sites, capacity, affinity, and biological significance of metals in melanin. J. Phys. Chem. B 111, 7938-7947 (2007).

22. Rowbotham, J., Dyer, P., Greenwell, H., Selby, D. \& Theodorou, M. Copper (II)-mediated thermolysis of alginates: a model kinetic study on the influence of metal ions in the thermochemical processing of macroalgae. Interface Focus 3, 20120046 (2013).

23. Schmidt, D. J. et al. Electrochemically controlled swelling and mechanical properties of a polymer nanocomposite. ACS nano 3 , 2207-2216 (2009).

24. Teng, C., Qiao, J., Wang, J., Jiang, L. \& Zhu, Y. Hierarchical Layered Heterogeneous Graphene-poly (N-isopropylacrylamide)-clay Hydrogels with Superior Modulus, Strength, and Toughness. ACS nano 10, 413-420 (2015).

25. Wang, J., Cheng, Q., Lin, L. \& Jiang, L. Synergistic toughening of bioinspired poly (vinyl alcohol)-clay-nanofibrillar cellulose artificial nacre. ACS nano 8, 2739-2745 (2014).

26. Lee, K.-M. et al. Improved adsorption properties of granulated copper hexacyanoferrate with multi-scale porous networks. RSC Adv. 6, 16234-16238 (2016).

27. Vijaya, Y., Popuri, S. R., Boddu, V. M. \& Krishnaiah, A. Modified chitosan and calcium alginate biopolymer sorbents for removal of nickel (II) through adsorption. Carbohydr. Polym. 72, 261-271 (2008).

28. Lee, Y.-C. et al. Aminoclay-induced humic acid flocculation for efficient harvesting of oleaginous Chlorella sp. Bioresour. Technol. 153, 365-369 (2014).

29. Kulesza, P. J., Malik, M. A., Denca, A. \& Strojek, J. In situ FT-IR/ATR spectroelectrochemistry of Prussian blue in the solid state. Anal. Chem. 68, 2442-2446 (1996).

30. Ishizaki, M. et al. Proton-exchange mechanism of specific $\mathrm{Cs}^{+}$adsorption via lattice defect sites of Prussian blue filled with coordination and crystallization water molecules. Dalton Trans. 42, 16049-16055 (2013).

31. Gotoh, A. et al. Simple synthesis of three primary colour nanoparticle inks of Prussian blue and its analogues. Nanotechnology 18 (2007).

32. Lu, Y., Wang, L., Cheng, J. \& Goodenough, J. B. Prussian blue: a new framework of electrode materials for sodium batteries. Chem Commun (Camb) 48, 6544-6546 (2012).

33. Lee, Y.-C., Kim, E. J., Ko, D. A. \& Yang, J.-W. Water-soluble organo-building blocks of aminoclay as a soil-flushing agent for heavy metal contaminated soil. J. Hazard. Mater. 196, 101-108 (2011).

34. Kang, K. S. et al. In-vitro cytotoxicity assessment of carbon-nanodot-conjugated Fe-aminoclay (CD-FeAC) and its bio-imaging applications. J. Nanotechnol. 13, 1 (2015).

35. Lee, Y.-C., Kim, M. I., Woo, M.-A., Park, H. G. \& Han, J.-I. Effective peroxidase-like activity of a water-solubilized Fe-aminoclay for use inimmunoassay. Biosens. Bioelectron. 42, 373-378 (2013).

36. Anal, A. K., Bhopatkar, D., Tokura, S., Tamura, H. \& Stevens, W. F. Chitosan-alginate multilayer beads for gastric passage and controlled intestinal release of protein. Drug Dev. Ind. Pharm. 29, 713-724 (2003).

37. Thomas, M., Naikoo, G. A., Sheikh, M. U. D., Bano, M. \& Khan, F. Fabrication of hierarchically organized nanocomposites of Ba/ alginate/carboxymethylcellulose/graphene oxide/Au nanoparticles and their catalytic efficiency in o-nitroaniline reduction. New J. Chem. 39, 9761-9771 (2015).

38. Oliver, W. C. \& Pharr, G. M. Measurement of hardness and elastic modulus by instrumented indentation: Advances in understanding and refinements to methodology. J. Mater. Res. 19, 3-20 (2004).

39. Yang, Y. et al. Quantitative measurement of cyanide released from Prussian Blue. Clinical Toxicology 45, 776-781 (2007).

40. Langmuir, I. The adsorption of gases on plane surfaces of glass, mica and platinum. J. Am. Chem. Soc. 40, 1361-1403 (1918).

41. Freundlich, H. Over the adsorption in solution. J. Phys. Chem. 57, e470 (1906).

42. Azizian, S. Kinetic models of sorption: a theoretical analysis. J. Colloid Interface Sci. 276, 47-52 (2004).

43. Rudzinski, W. \& Plazinski, W. Kinetics of solute adsorption at solid/solution interfaces: a theoretical development of the empirical pseudo-first and pseudo-second order kinetic rate equations, based on applying the statistical rate theory of interfacial transport. $J$. Phys. Chem. B 110, 16514-16525 (2006).

44. Deze, E. G., Papageorgiou, S. K., Favvas, E. P. \& Katsaros, F. K. Porous alginate aerogel beads for effective and rapid heavy metal sorption from aqueous solutions: effect of porosity in $\mathrm{Cu}^{2+}$ and $\mathrm{Cd}^{2+}$ ion sorption. Chem. Eng. J. 209, 537-546 (2012).

45. Sangvanich, T. et al. Selective capture of cesium and thallium from natural waters and simulated wastes with copper ferrocyanide functionalized mesoporous silica. J. Hazard. Mater. 182, 225-231 (2010).

46. Chen, R. et al. Thermodynamics and mechanism studies on electrochemical removal of cesium ions from aqueous solution using a nanoparticle film of copper hexacyanoferrate. ACS Appl. Mater. Interfaces 5, 12984-12990 (2013).

47. Martin, J. E., Patil, A. J., Butler, M. F. \& Mann, S. Guest-Molecule-Directed Assembly of Mesostructured Nanocomposite Polymer/ Organoclay Hydrogels. Adv. Func. Mater. 21, 674-681 (2011).

48. Yang, L. et al. Biodistribution and clearance of aminoclay nanoparticles: implication for in vivo applicability as a tailor-made drug delivery carrier. J. Mater. Chem. B 2, 7567-7574 (2014).

49. Chandrasekaran, G., Han, H.-K., Kim, G.-J. \& Shin, H.-J. Antimicrobial activity of delaminated aminopropyl functionalized magnesium phyllosilicates. Appl. Clay Sci. 53, 729-736 (2011).

50. Chaturbedy, P., Jagadeesan, D. \& Eswaramoorthy, M. pH-sensitive breathing of clay within the polyelectrolyte matrix. ACS nano 4, 5921-5929 (2010).

51. Burkett, S. L., Press, A. \& Mann, S. Synthesis, characterization, and reactivity of layered inorganic-organic nanocomposites based on 2: 1 trioctahedral phyllosilicates. Chem. Mater. 9, 1071-1073 (1997). 


\section{Acknowledgements}

This work was supported by the Radiation Fusion Technology Program (2015M2A2A6A02045262(3)) from Nuclear Research R\&D Program through the National Research Foundation of Korea (NRF) funded by the Ministry of Science, ICT \& Future Planning (MSIP), Korea and Inha University.

\section{Author Contributions}

S.-C.J., S.-M.K. and Y.S.H. conceived the idea, designed the research and performed the experiments and analyzed the data. S.-C.J., Y.H., K.G. and Y.S.H. wrote the main manuscript. G.-W.L. performed the SEM and EDS characterization. Y.-C.L. and Y.-K.H. supported discussed the interpretation of results. C.R. and Y.S.H. supervised the research. All authors discussed the results and reviewed the manuscript.

\section{Additional Information}

Supplementary information accompanies this paper at http://www.nature.com/srep

Competing financial interests: The authors declare no competing financial interests.

How to cite this article: Jang, S.-C. et al. Synergistically strengthened 3D micro-scavenger cage adsorbent for selective removal of radioactive cesium. Sci. Rep. 6, 38384; doi: 10.1038/srep38384 (2016).

Publisher's note: Springer Nature remains neutral with regard to jurisdictional claims in published maps and institutional affiliations.

(c) (i) This work is licensed under a Creative Commons Attribution 4.0 International License. The images or other third party material in this article are included in the article's Creative Commons license, unless indicated otherwise in the credit line; if the material is not included under the Creative Commons license, users will need to obtain permission from the license holder to reproduce the material. To view a copy of this license, visit http://creativecommons.org/licenses/by/4.0/

(C) The Author(s) 2016 